\title{
Os trânsitos para a cultura impressa. Marín, Avellaneda e a escritura pública no século XIX hispano-americano ${ }^{1}$
}

\author{
Transitions towards print culture. Marín, Avellaneda and public \\ writing in the Hispanic American $19^{\text {th }}$ century
}

https://doi.org/10.34112/2317-0972a2021V39n83p65-79

\section{Guadalupe Correa Chiarotti ${ }^{2}$}

Resumo: Ao longo do século XIX, as mulheres travaram lutas tenazes em várias frentes. Talvez uma das mais sutis - mas também uma das mais implacáveis - tenha sido o campo da cultura e, mais especificamente, aquela parte que corresponde à literatura. Se se encontravam com mil objeções na leitura feminina e se até a escrita privada trazia perigos de todos os tipos, quantos riscos as mulheres não encontraram na publicação e na consequente exposição pública? Nas páginas que se seguem, vamos nos deter em alguns trechos editoriais em que são ensaiadas estratégias argumentativo-editoriais capazes de converter os preconceitos masculinos em condições de possibilidade para o acesso de mulheres ao mundo das letras.

Palavras-chave: Cultura impressa; mulheres; séc. XIX; leitoras.

ABSTRACT: Throughout the $19^{\text {th }}$ century, women strove in various frontlines. Conceivably the most subtle front -however a relentless one- was the cultural sphere, namely in the domains of literature. If numerous objections were found in feminine reading, still if private

1. Agradeço a Lilian C. de C. Martinez pela colaboração na tradução destas páginas, a oportunidade de compartilhar este trabalho no ciclo de conferências "Dissertações em vozes femininas", organizado pela Universidade de Cartagena e a Universidade Tecnológica de Bolívar (Colômbia) e, especialmente, minha colega Giobanna Buenahora Molina.

2. Acadêmica da Universidad Autónoma Metropolitana - México. 
writing presented all sorts of perils, how many risks were not taken by women in publishing and the ensuing public exposition? In the following pages we will analyze some editorial extracts where argumentative and editorial strategies were practiced and were capable of transforming masculine prejudice into circumstances to gain access to the literary realm. KeYwords: Print culture; women; 19th century; female reader.

No século XIX, o século das revoluções emancipatórias americanas e de uma maior produção de obras, as mulheres foram aves raras que publicaram pouquíssimos livros. Essa constatação é sinônimo de que elas escreveram pouco? Certamente, menos do que os homens: elas não tinham instrução elementar suficiente, o tempo necessário ("roubado" pelo serviço doméstico), condições econômicas e de profissionalização; caberia aqui um longuíssimo etcetera. $\mathrm{O}$ mundo dos livros também era eminentemente masculino, desde o processo criativo inicial, passando pela fase de reprodução técnica, até a venda, a compra, e, hipoteticamente, a leitura.

No entanto, essa situação vai mudando ao longo do século. Uma série de reivindicações fundamentais, como o acesso à educação e à participação na vida pública, deixam de ser impulsos atomizados das sociedades pós-independentistas para se converterem em direitos adquiridos (embora, é claro, omitidos ou arrebatados com grande facilidade). Esse trânsito, essa passagem do silêncio estrito - imposto por uma série de atribuições coercitivas - para a possibilidade relativa de escrever literatura (e de lê-la), pode ser observada em alguns fragmentos retirados das obras da chilena Mercedes Marín del Solar (1804-1866) e da cubana Gertrudis Gómez de Avellaneda (1814-1873).

Por que essas mulheres e não outras? Porque são as únicas cujas composições foram incluídas na América poética, primeira antologia semi-continental de poesia. Este volume, substrato de todos os compêndios posteriores e definidor da conformação de um cânone (mas também de um corpus), foi compilado pelo exilado argentino Juan María Gutiérrez e publicado em Valparaíso, entre 1846 e 1847 (13 entregas colecionáveis). De um índice composto por 53 nomes, Marín e Avellaneda são as duas únicas mulheres admitidas neste "areópago dos poetas americanos" - como batizou Sarmiento. A qualidade de excepcionais que corresponde a essas escritoras é, sem dúvida, manifesta, mas também suas formas de contornar as margens: ambas poetas, muito diferentes, muito distantes, mas ambas determinadas a articular dispositivos editoriais argumentativos que influenciam a publicação de suas obras líricas. 
“O CONHECIMENTO REMOTO DOS LIVROS”: ENTRE O GOZO SEM FIM E A AMBIÇÃO PERIGOSA

Alguns meses depois do início da publicação da América poética (fevereiro de 1846) e próximo da letra $\mathrm{M}$ - de acordo com os critérios alfabéticos que regem o volume -, Gutiérrez pede a Mercedes Marín del Solar composições e notícias biográficas para o verbete correspondente. Nascida em Santiago (1804) em plena revolução e no seio de uma família rica, conservadora, católica e letrada, ${ }^{3}$ del Solar gozou de uma educação culta e de um tratamento intelectual, o que pode ser considerado um privilégio para a época. Entre suas notas biográficas está o fato de ser considerada pela historiografia literária como a primeira poetisa chilena a entregar seus versos para imprimir: em lançamentos iniciais, em jornais e, postumamente, em forma de livro. ${ }^{4}$ Paradoxalmente, ela não publicou nenhum livro em sua vida.

Juan María Gutiérrez inicia sua apresentação com a transcrição de um trecho de um discurso proferido em uma escola feminina, o qual copia de jornais (cabe ressaltar), e que, por sua vez, retomamos para escutar del Solar, cuja voz se esgueira nos interstícios do livro (modulada, claro, pelo próprio Gutiérrez):

La historia, la literatura, las bellas artes, os ofrecen sus inmensos tesoros: a todo puede elevarse vuestra intelijencia, que no cede en viveza y penetración a la del hombre. De todo podeis gozar sin mengua de vuestras gracias naturales, $y$ sin contrariar el destino que os ha deparado la providencia. Pero no es mi ánimo despertar en vosotras una ambición peligrosa: sé que el destino de la mujer es oscuro, y que el camino de la gloria está para ella erizado de espinas y cubierto de precipicios: no obstante, su vida que en gran parte forma la consagración al deber, y una modesta sumisión a las conveniencias sociales, puede aun estar llena de encantos, si la sensibilidad y las luces, reunidas en proporcion, forman los elementos de su carácter... La solemnidad de este acto os dejará las más puras e indelebles impresiones. Vosotras lo recordareis con gusto cuando mas adelantadas en la vida, conozcáis el precio de la inocencia y del reposo; porque los goces de la virtud no se

3. Seu pai era José Gaspar Marín, secretário do Primeiro Conselho Nacional de Governo do Chile; seu irmão, Ventura Marín, publicou importantes livros sobre filosofia e religião; seus filhos, Amélia e Enrique, também publicaram obras literárias.

4. Poesías de la señora Doña Mercedes Marín de Solar, editadas por seu filho Enrique de Solar em 1874, em Santiago. Joyce Contreras Villalobos publicou recentemente uma edição crítica necessária de sua obra: Mercedes MARÍN DEL Solar. Obras reunidas. Compilación, estudio preliminar y notas críticas de J. Contreras Villalobos. Santiago de Chile: Dirección de Bibliotecas, Archivos y Museos, 2015. 
Os trânsitos para a cultura impressa. Marín, Avellaneda e a escritura...

borran jamás y su memoria, como la de la infancia, esparce una suave y encantadora luz aun en los confines del sepulcro (MARÍN in GUTIÉRREZ, 1846, p. 524).

A partir dessa citação substancial, podemos apontar vários elementos de relevo. Em primeiro lugar, a reinvindicação pela inteligência das mulheres, que em muitos aspectos soa como a demanda americanista tão viva no período pós-revolucionário. Lembremos que, naqueles dias, a proclamação da igualdade entre as habilidades intelectuais americanas e europeias é tema de ensaística local, preocupada em transferir ao plano das ideias e das artes os triunfos militares e, assim, alcançar o reconhecimento internacional que endossasse a independência política. ${ }^{5}$ Em outras palavras, se a bandeira da igualdade fez a sociedade americana diferenciar-se ante as nações do mundo, por que esse entendimento não seria estendido, por sua razão civilizadora, para a outra metade subjugada pela ignorância?

Nesse sentido, se muitos americanistas, como o próprio Gutiérrez, buscaram argumentos para convencer sobre a capacidade intelectual dos americanos - de que não estavam condenados pelo ambiente a produzir obras culturais menores, como preconizavam as teorias deterministas europeias em voga -, Mercedes Marín parte de uma ideia positiva, categórica, posiciona-se a partir da segurança que dá a certeza de um fato inapelável: "La historia, la literatura, las bellas artes, os ofrecen sus inmensos tesoros: a todo puede elevarse vuestra inteligencia, que no cede en viveza y penetración a la del hombre. De todo podéis gozar sin mengua de vuestras gracias naturales, y sin contrariar el destino que os ha deparado la providencia”. Estas palavras, dotadas de forte tom afirmativo, não se limitam à mera possibilidade pedagógica, ao direito de acesso à história, à literatura e às artes (repare na distinção: não política ou filosofia), mas apelam às mulheres para gozar dessas disciplinas, para exercer uma compreensão enérgica e expansiva, para "consumir vanidades de la vida", como bem diria a poetisa sor Juana. ${ }^{6}$ Não há nada nestas palavras que vá contra o preceito religioso.

5. Essa “disputa do Novo Mundo", tão antiga quanto persistente, essa ânsia por equiparar as potências artísticas, se manifesta também na própria América poética, obra concebida em grande parte por razão desse impulso: "Nos guía en la publicación [... ] una intención muy seria. La tenemos por un acto de patriotismo, mirando en ella uno de los testimonios que aún faltan para convencer de que en el pensamiento americano hay elevación, nobleza y unidad” (Gutiérrez, 1846, p. V).

6. Soneto núm. 146 de sor Juana Inés de la Cruz, no qual “Quéjase de la suerte: insinúa su aversión a los vicios, y justifica su divertimiento a las Musas”: "En perseguirme, Mundo, ¿qué interesas? / ¿En qué te ofendo, cuando sólo intento / poner bellezas en mi entendimiento / y no mi entendimiento en las bellezas? // Yo no estimo tesoros ni riquezas; / y así, siempre me causa más contento / poner riquezas en mi entendimiento 
No entanto, Marín logo se dá conta das consequências morais de seus ditos e, em seguida, restringe seu discurso, ainda que em um contexto semipúblico e diante de um auditório que imaginamos eminentemente feminino (ou, talvez, por isso) ": "Pero no es mi ánimo despertar en vosotras una ambición peligrosa: sé que el destino de la mujer es oscuro, y que el camino de la gloria está para ella erizado de espinas y cubierto de precipicios". A autora limita a significação libertária de seu discurso não por falta de aptidões intelectuais, mas pelos perigos que tais inclinações trazem. Não faltam, na história das mulheres, exemplos de como o desejo de saber acarreta riscos capazes de arrastar sua honra e desequilibrar sua sanidade (quase invariavelmente: prostitutas ou loucas).

No século XIX, a "perigosa ambição" feminina de estudar desperta suspeitas muito precisas no campo literário: a leitura é aceita apenas em determinados momentos e em espaços privados (muitas vezes domésticos e fortemente vigiados). Quanto aos temas admitidos, eles se limitam a assuntos piedosos ou manuais de civilidade ou técnicas aplicadas ao lar (CRAMPE-CASNABET, 2000). O romance, aliás, é objeto de desconfiança, principalmente na medida em que poderia acender um imaginário já exuberante nas mulheres e despertar desejos não necessariamente condizentes com a instituição da família (o caso das leituras de Madame Bovary é paradigmático) ${ }^{9}$. Não vou me deter neste ponto, mas gostaria de apontar apenas uma aresta. Uma das expectativas mais comuns associadas à leitura era o seu fim utilitário, posto que a edificação moral deveria ser, segundo certo ponto de vista, o último fim dessa atividade, que, longe de ser lúdica, deveria ser proveitosa. Em outras palavras: a ociosidade, o gozo e o prazer no ato de ler representariam um risco alto, pois o prazer pelo prazer não persegue uma instrução, abandona-se ao seu puro deleite hedonista, exercendo uma influência corruptora da virtude feminina.

/ que no mi entendimiento en las riquezas. // Yo no estimo hermosura que, vencida, / es despojo civil de las edades / ni riqueza me agrada fementida, / / teniendo por mejor, en mis verdades, / consumir vanidades de la vida / que consumir la vida en vanidades.. Em sor Juana Inés de la Cruz. Obras completas, t. i: Lírica personal. $2^{\mathrm{a}}$ ed. [ $1^{\mathrm{a}} 1951$ ], ed. de Antonio Alatorre. México: Fondo de Cultura Económica, 2009, p. 388-389.

7. Lembremos que é um prêmio em um colégio para moças.

8. Tradução livre: "Mas não é minha intenção despertar em vocês uma ambição perigosa: eu sei que o destino da mulher é escuro, e que o caminho da glória para ela é eriçado de espinhos e coberto de precipícios”.

9. Em Madame Bovary (aparecida em $1856 \mathrm{em}$ forma de folhetim e em $1857 \mathrm{em}$ formato livro), Gustave Flaubert descreve Emma como fervente leitora de novelas românticas, fato que se enlaça diretamente com o andar desenfreado de sua fantasia (contra o fundo cinza de sua realidade monótona) e, finalmente, com seu destino fatídico: casos extraconjugais, dívidas e suicídio. 


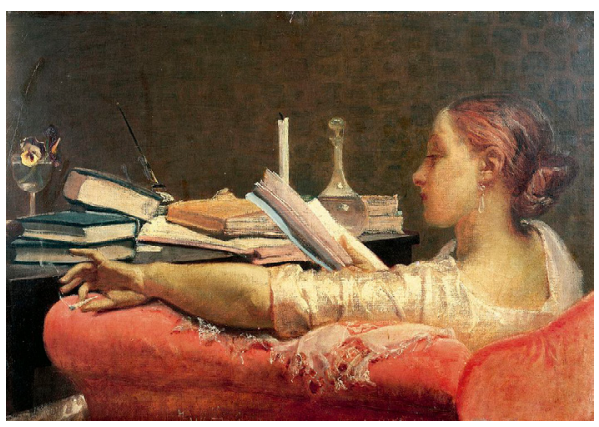

1. Federico Feruffini, Le lettrice (o Clara), 1864.

É claro que esse debate em torno do romance e seus efeitos perniciosos não dizia respeito a todas as mulheres, nem mesmo a uma maioria. Um grupo muito pequeno e seleto podia ser presenteado com uma habilidade básica e de classe: 0 domínio da leitura. Como é sabido, as taxas de analfabetismo nos países hispano-americanos são altíssimas em termos gerais (e muito variáveis com o passar do século), mas muito mais dramáticas quando se referem exclusivamente às mulheres, para as quais a disparidade em relação aos homens se torna escandalosa ${ }^{10}$. E se a assimetria nos parece infame, quanto mais olhamos para as diferenciações internas, mais se percebe outra brecha, a que ocorre entre mulheres pobres e mulheres ricas.

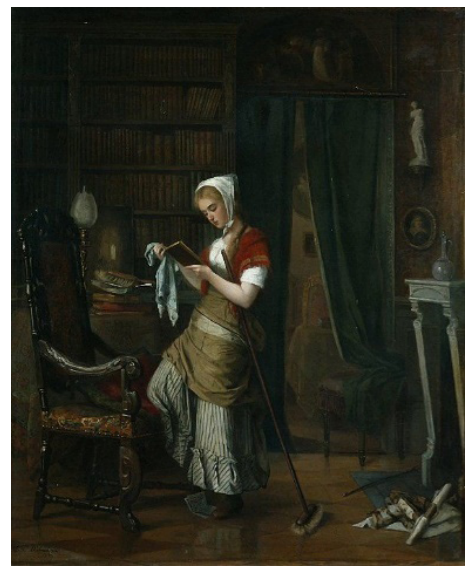

2. Johanne Dietrichson, O interior de uma casa de campo, 1875.

10. No Chile, segundo dados recolhidos por Doll Castillo, "en el censo realizado en 1854 se consigna que del $100 \%$ de las mujeres chilenas, solo el 10\% sabía leer”. (2007, p. 85). 
Na pintura da norueguesa Johanne Dietrichson, O interior de uma casa de campo (1875), os comentaristas notaram o poder de distração que a leitura pode trazer a uma jovem trabalhadora, que abandona o trabalho doméstico por um momento. Porém, a partir dessas culturas, esse deslize profissional é menos perceptível do que o fato de uma "criada" ter a educação formal necessária para ler, diferença perceptível entre o norte e o sul globais.

Voltemos ao caso específico da chilena Mercedes Marín. Na ocasião de responder ao pedido do antologista, o jovem Gutiérrez, sobre as suas notícias biográficas, a escritora se dispensa de dá-las formalmente, na medida em que tenta canalizar a interpretação da sua atividade escrita para um típico artifício concebido das margens da subordinação (LUDMER 1985): "V. puede poner mis versos en su colección como una suerte de curiosidad por ser una mujer americana que no ha tenido educación literaria y que debe sus inspiraciones a la pura naturaleza sin otra influencia externa que alguna ligera afición a la lectura" (GUTIÉRREZ, 1981, p. 69)." O tópico, agora com legitimação romântica, faz da paixão o impulso da escrita: ela escreve porque isso está em sua natureza sensível e fecunda, não porque é o desenlace lógico de uma compreensão ativa. Ser mulher escritora é, antes e depois de sor Juana, ser rara avis in terris.

No entanto, como qualquer treta ${ }^{12}$, omite certos eventuais acontecimentos de sua biografia. De acordo com sua origem, a escritora tem uma formação esmerada, que lhe permite não só ler e escrever, mas também acessar o gênero letrado por excelência - pelo menos neste século: a poesia. Como se explica esse refinamento estético diante do deserto institucional-educacional de nossos países naqueles anos? Joyce Contreras Villalobos e Damaris Landeros Tiznado dedicaram um excelente estudo à figura de Mercedes Marín, no qual analisam múltiplos aspectos de suas facetas intelectuais (salonière, educadora e poetisa), todas voltadas, de uma forma ou de outra, para a construção patriótica de uma nação brotando. Atribuem a capacidade intelectual da autora a um exemplo preciso do século XIX: o salão.

11. Carta de Mercedes Marín de Solar, Santiago de Chile, a Juan María Gutiérrez, com data de 1 de setembro de 1846.

12. O termo se refere ao artigo de Ludmer, citado na bibliografia. 


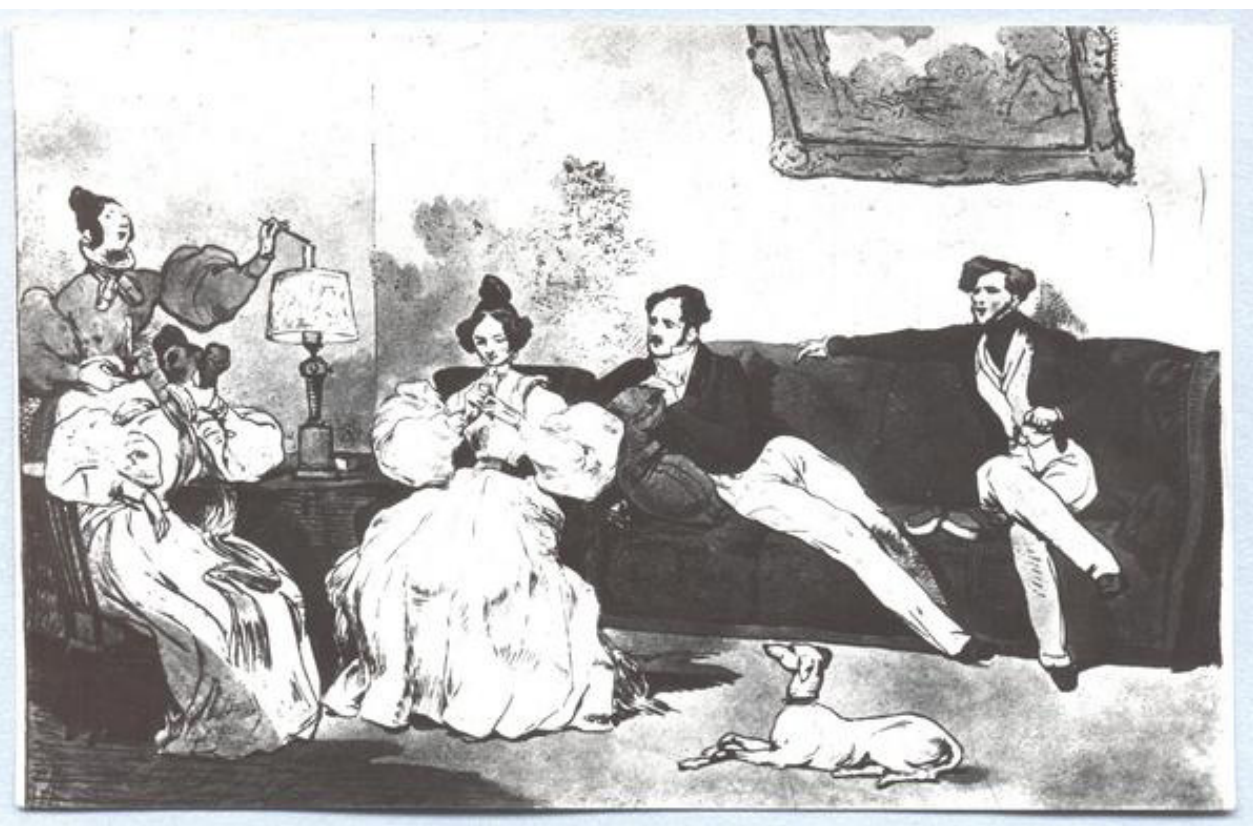

3. Mauricio Rugendas, Tertulia en la casa del coronel Eduardo Gutike en Talca, 1836.

De acordo com as autoras (2014), o salão constitui um passaporte para facilitar o movimento feminino rumo ao espaço cultural; é uma instância intermediária entre a oralidade e a escrita, o público e o privado, incentiva a autoexpressão (aparece a opinião feminina), a autoformação (ver também DOLL CASTILLO, 2007) e permite uma certa conquista de capital cultural e social. Pelo salão Mercedes passaram, entre outros, Mauricio Rugendas (pintor bávaro que retrata a experiência), Andrés Bello e Juan Maria Gutiérrez ${ }^{13}$.

PARA UMA MULHER, PUbLICAR É JOGAR SUA SORTE À MAIS TERRÍVEL DAS LOTERIAS

Para a apresentação que antecede a seleção dos poemas, Gutiérrez recolhe fragmentos da carta pessoal a que acabamos de fazer referência, na qual Mercedes

13. Se nesta ocasião encontramos Bello participando dos salões de Marín, primeiro o encontramos na trama editorial de seu crescente público: foi ele quem pela primeira vez deu a conhecer seu poema a Portales (a que nos referiremos mais adiante), que se tornaria popular em seu meio. 
evidencia sua discrição e sua dedicação prioritária ao cuidado dos filhos, talvez com uma modéstia excessiva:

Ajena toda la vida de pretensiones al saber, sólo he escrito cuando alguna fuerte emoción o alguna indispensable condescendencia me ha puesto la pluma en la mano... Desde muy temprano me hicieron entender mis padres que cualquiera que fuese la instrucción que yo llegase a adquirir por medio de la lectura, era necesario saber callar. Cuando empecé a reflexionar por mí misma conocí cuán acertado era a este respecto su modo de pensar, y exagerándolo, tal vez en demasía, juzgué que una mujer literata en estos países era una clase de fenómeno extraño, acaso ridículo, y que un cultivo esmerado de la inteligencia exigía de mí, hasta cierto punto, el sacrificio de mi felicidad personal... [...] Mis versos son como un lujo de mi vida privada, y no pocas veces han contribuido a librarme de alguna fuerte y dolorosa impresión (MARÍN in GUTIÉRREZ, 1846, p. 524-525).

Deste fragmento, recuperado e comentado pela crítica com muita sorte, ${ }^{14}$ gostaria de enfatizar apenas algumas passagens. Em primeiro lugar, a necessidade de esconder os méritos: se se sabe, é melhor calar. Em segundo lugar, o ridículo de ser uma mulher literata, a antítese depreciativa de seu homônimo masculino autorizado: existiu, naquela época, uma espécie de vínculo impossível entre felicidade e escrita, com repercussões de longo alcance na vida privada das mulheres das letras.

E se alguém teve plena consciência do atributo extravagante e grotesco que o exercício da escrita implicava, foi Gertrudis Gómez de Avellaneda, talvez a mais famosa poetisa e dramaturga hispano-americana do século XIX. Em sua Autobiografia inicial (tinha 25 anos), ${ }^{15}$ a cubana expõe de modo exemplar como é percebido seu compromisso com a escrita por um de seus admiradores, o galego Ricafort:

14. Graciela Batticuore encontrou neste escrito uma expressão exemplar de la autoría atenuada: "puede decirse que la carta de esta interlocutora de los románticos argentinos nos ofrece un ejemplo de lo que denomino la autoría atenuada, en tanto que, precisamente, la escritora modera, posterga o bien subordina la publicación de sus textos al reclamo ajeno, con tal de resguardar su "independencia" (que implica aquí la libertad de não ser observada por los outros y, por tanto, de eleger sin restricciones las lecturas y escrituras que practica), y eludiendo una "reputación" (la de "literata") para la cual su vida y su entorno no están preparados. La decisión de publicar poco o nada es, precisamente, una opción no espontánea sino meditada y calculada por ella, que medirá oportunamente cada ocasión y cada reclamo, de acuerdo con la conveniencia personal y familiar y no con la vocación por las letras”. (2005, p. 116).

15. Este caderninho foi redigido em julho de $1839 \mathrm{em}$ Sevilha e teve por fim cativar a Ignacio de Cepeda; ele o conservou e foi publicado por sua viúva em 1907, ainda que exigisse em sua primeira página "que el fuego 
Os trânsitos para a cultura impressa. Marín, Avellaneda e a escritura...

Su talento no correspondía a su corazón: era muy inferior por desgracia mía. Conocí pronto esta desventaja: aunque generoso Ricafort parecía humillado de la superioridad que me atribuía: sus ideas e inclinaciones contrariaban siempre las mías. No gustaba de mi afición al estudio y era para él un delito que hiciese versos. Mis ideas sobre muchas cosas le daban pena e inquietud. Temblaba de la opinión, y decíame muchas veces: “¿Qué lograrás cuando consigas crédito literario y reputación de ingenio? Atraerte la envidia y excitar calumnias y murmuraciones" (2014b, p. 413).

Em ambas poetisas, um fato se destaca: o exercício da escrita pode chegar a causar problemas, mas o que é realmente perigoso, ou pelo menos perturbador, é a exposição da escrita, isto é, a publicação. As razões, como não surpreende, são organizadas em torno de argumentos estritamente morais: má reputação e honra.

É comum ao longo do século XIX - mas mesmo muito antes e inclusive depois - referir-se às desventuras que a publicação acarreta para as mulheres. Stendhal, no início do século 19, alertou: "Para una mujer de menos de cincuenta años, publicar es jugar su suerte a la más terrible de las loterías; si tiene la fortuna de tener un amante, comenzará por perderle. [... Sólo a una mujer de vida alegre le es dado publicar sin inconveniente un libro" (cit. em BATTICUORE, 2005, p. 114). Esses exemplos representam evidências eloquentes de como a publicação representa um risco significativo para o decoro feminino, cuja voz deve permanecer em redutos estreitos e cuja escrita não deve transcender o espaço privado.

Tanto no jornal diverso e curto - mais acessível no preço e focado na novidade e na instrução geral -, quanto num livro sólido e perdurável, a verdade é que as mulheres tinham poucas possibilidades de publicar; menos ainda, poesia: "La publicación de un tomo de poesías, aun en lengua vulgar, escritas por una mujer, no es cosa muy frecuente en ningún país: en el nuestro [España] es rarísima” (GALLEGO, 1841, p. IV). Outra vez a rareza, enquanto qualidade extraordinária, é o qualificador que melhor se adequa à participação de uma escritora na cidade letrada do século XIX.

Juan Nicasio Gallego, eminente poeta espanhol (elo entre o neoclassicismo e o romantismo), levanta a questão justamente a respeito da publicação do primeiro volume da poesia de Gertrudis Gómez de Avellaneda:

devore este papel inmediatamente que sea leído" e, imediatamente, "que nadie más que usted en el mundo tenga noticia de que ha existido" (p. 391). 
Desacreditada ya muchos años hace la opinión absurda de que toda clase de ilustración era perniciosa a las mujeres, opinión que tan autorizada estuvo en la primera mitad del último siglo, y siento tan general en el bello sexo la afición a las lecturas amenas, la asistencia al teatro, el estudio de los idiomas italiano y francés y el de la música y el dibujo [...], ¿ cómo es que hay tan pocas que despunten por componer versos, y menos las que se atrevan a publicarlos? No es difícil descubrir las causas, que en nuestra opinión no son otras que el temor del ridículo y ciertas preocupaciones de que vemos poseídas a muchas personas que se ofenderían de que se las llamase vulgo. A lo primero han contribuido muy principalmente los poetas satíricos de todas las épocas, los cuales por lisonjear el orgullo varonil, se han extremado en ridiculizar en las mujeres la afición a las letras. Algunas de nuestras comedias antiguas $[\ldots]$ bastan y sobran para intimidar a las más audaces, y el apodo de doctoras y marisabidillas les pone espanto. Por otra parte es sobrado común la creencia de que el talento de hacer versos está siempre asociado a un carácter raro y estrambótico, que la vena de poeta y la de loco son confines, y que la mujer dada a tales estudios es incapaz de atender a los cuidados domésticos, a los deberes de la maternidad y a las labores del bastidor y de la almohadilla. Este concepto es tan general, que muchos de aquellos mismos que ensalzan hasta las nubes las obras literarias de una mujer, y encarecen su instrucción y talento, son los primeros que por esa sola circunstancia la rehusarían por esposa (1841, p. VI-VII).

Ridículo, raridade e loucura: aqui estão os atributos associados à escrita feminina. Em síntese: Mujer que sabe latín, no tiene marido, ni tiene buen fin. Tal é, ao que parece, o mandato social prevalecente e a medida estreita do código que o prescreve.

\section{Como tentativa de Conclus ão. A Paixão legitimadora do destino POÉTICO}

Apesar desta forte condenação social, as mulheres não desistem de empreender uma tarefa que sabem de antemão ser arriscada. Escrever é, em si, um ato que desafia a ideologia patriarcal. Essa afirmação, é claro, tem nuances diferentes dependendo do gênero literário e do contexto: escrever poesia como panfleto político não é a mesma coisa que publicar em álbum de amigos ou em um jornal de grande circulação. Marín é, neste plano, um caso curioso, pois publica poesia em jornais, o que certamente não é pouco usual. O que é mais estranho é que seu tema é político, ou histórico, como se vê: seu poema mais famoso, aquele que a tornou popular entre 
o povo, e o mesmo que a inscreveu na história da literatura chilena como a primeira mulher escritora (AMUNÁTEGUI 1892), é um "Canto fúnebre a la muerte de don Diego Portales” (GUTIÉRREZ 1846, p. 525-529).

Diego Portales era o líder de uma facção conservadora, um político acusado pela dureza de suas medidas, considerado ditador por alguns, promotor da ordem e dissipador da anarquia por outros. Sua trágica morte, ao amanhecer, por amotinados, com disparos pelas costas e abatido com uma baioneta, causou grande ansiedade na sociedade chilena. Este estado generalizado causou forte impressão em Marín, que, numa nota enviada a Gutiérrez ex profeso (de 25 de agosto de 1846) e que acompanha seu poema na América poética, vê a necessidade de se abster dos elogios que faz a um personagem e dizer que o mesmo "tem admiradores entusiastas e detratores apaixonados”. Alheia à defesa do ministro e assumindo uma voz equânime nas disputas políticas, a chilena justifica seu canto alegando uma certa catarse social, um certo senso de identidade compartilhado, um certo luto coletivo que encontra nela um veículo idôneo de expressão. Em suas palavras:

Estos antecedentes [el accionar político de Portales], unidos al carácter alevoso y trágico de su muerte, excitaron por él una vehemente simpatía, que suspendiendo toda animosidad y antiguo resentimiento, obligó al pueblo chileno a derramar sobre su sepulcro, sincero y amargo llanto. Yo me sentí conmovida hasta lo íntimo del alma; y con todo, no he creído ser otra cosa en aquellos días, que intérprete fiel del sentimiento general. (MARÍN in GUTIÉRREZ, 1846, p. 525).

Se, por um lado, ela deve se abster de se envolver em questões políticas (já sabemos que essa questão está estritamente reservada ao monopólio masculino, o "exclusivismo varonil", como diria Gertrudis), por outro lado encarece o valor sentimental e necessário de sua escrita. Antes, na carta que dirige a Gutiérrez, carrega nas tintas sobre esse ponto: "Ajena toda la vida de pretensiones al saber, sólo he escrito cuando alguna fuerte emoción o alguna indispensable condescendencia me ha puesto la pluma en la mano [... ] Mis versos son como un lujo de mi vida privada, y no pocas veces han contribuido a librarme de alguna fuerte y dolorosa impresión" (MARÍN in Gutiérrez, 1846, p. 524-525). Marín apela ao poder da emoção para poetizar sobre um dos personagens mais polêmicos da política chilena contemporânea.

Movimento interessante, talvez outro de seus muitos artifícios. Se a voz da autoridade (masculina, patriarcal e canônica) questiona a excessiva afetividade feminina, então Marín, mas também Avellaneda, assumem-se naquele lugar imposto, pré-atribuído, violento como qualquer mandato, para convertê-lo e ressignificá-lo. Elas 
escrevem sobre a afetividade para, sem mais delongas, escrever, o que é - em si - um ato de desobediência. Na sua condição de mulheres, não renegam, de forma direta, $o$ que se constitui como ofensa devido à parcialidade do julgamento da que são objeto. Ao invés disso, se apropriam da afronta, a assumem e a destroem, enunciando uma vez mais e, assim, ampliando as possibilidades do gênero (poético e de identidade social) com os seus próprios resquícios discursivos. Observemos esse movimento em um conhecido ensaio de Gertrudis Gómez de Avellaneda, "Reflexões sobre as mulheres".

Neste escrito, dividido em várias seções (publicado em fascículos na imprensa espanhola antes da forma unitária), inicia-se a exposição partindo do imaginário aceito e generalizado, que finca no emocional a virtude feminina por excelência.

Concedemos sin la menor repugnancia que en la dualidad que constituye nuestra especie, el hombre recibió de la naturaleza la superioridad de la fuerza física, y ni aun queremos disputarle en este breve artículo la mayor potencia intelectual, que con poca modestia se adjudica. Nos basta, lo declaramos sinceramente, nos basta la convicción de que nadie pueda de buena fe, negar a nuestro sexo la supremacía en los afectos, los títulos de su soberanía en la inmensa esfera del sentimiento (GÓMEZ DE AVELLANEDA, 2014a, p. 368).

Gertrudis ocupa um lugar comum, geralmente admitido: corresponde às mulheres o domínio da paixão e das emoções (em contraste com o poder eminentemente racional dos homens). Mas esse reconhecimento não é degradante, pelo contrário: serve para levantar um apelo a favor da escrita: se nos corresponde a parte sensual, isto é, a parte que percebe o mundo da efusão natural, então se torna legítimo que façamos arte, já que é o substituto lógico da expressão emotiva. Dito na língua das musas:

Dame que pueda entonces, ¡virgen de paz! ¡sublime poesía!

no trasmitir en mármoles y bronces de un siglo en otro la memoria mía, sólo arrullar, cantando, mis dolores, la sien ceñida de modestas flores. (1841, p. 16) 
Os trânsitos para a cultura impressa. Marín, Avellaneda e a escritura...

\section{REFERÊNCIAS}

AMUNÁTEGUI, M. L. La alborada poética en Chile después del 18 de setiembre de 181o. Santiago de Chile: Imprenta Nacional, 1892.

BATTICUORE, G. La mujer romántica. Lectoras, autoras y escritores en la Argentina: 1830-1870. Buenos Aires: Edhasa, 2005.

CONTRERAS VILLALOBOS, J.; LANDEROS TIZNADO, D. Mercedes Marín: las múltiples facetas de una mujer moderna (saloniére, educadora, poeta). Su participación en la configuración del ideario nacional. In: GUARDIA S. B. (Ed. y Comp.). Las mujeres en los procesos de Independencia de América Latina. Lima: CEMHAL, UNESCO, USMP, 2014. p. 269-278.

CONTRERAS, J. La resistencia al libro. Mujeres, escritura y exclusión en el siglo xIx en Chile. In: ACERO N.; CÁCERES. J.; HERRERA PARDO, H. (Eds.). Vestigio y especulación. Textos anunciados, inacabados y perdidos de la literatura chilena. Santiago: Chancacazo Publicaciones, 2014 (Colección pensamiento).p. 99-138.

CRAMPE-CASNABET, M. Las mujeres en las obras filosóficas del siglo XVIII. In: DUBY, G.; PERROT, M. Historia de las mujeres en Occidente, 3 vol.: Del Renacimiento a la Edad Moderna. Trad. de Marco Aurelio Galmarini. Madrid: Taurus Minor/Santillana, 2000 [Storia delle donne, 1990]. p. 344-384.

DOLL CASTILLO, D. Desde los salones a la sala de conferencias: mujeres escritoras en el proceso de constitución del campo literario en Chile. Revista Chilena de Literatura, n. 71, p. 83-100, 2007.

GALLEGO, J. N. Prólogo. In: GÓMEZ DE AVELLANEDA, G. Poesías. Madrid: Establecimiento tipográfico, Calle del Sordo núm. 11, 1841. p. I-XIII.

GÓMEZ DE AVELLANEDA, G. Poesías. Pról. de Juan Nicasio Gallego. Madrid: Establecimiento tipográfico, Calle del Sordo núm. 11, 1841.

GÓMEZ DE AVELLANEDA, G. Reflexiones sobre la mujer. In: GÓMEZ DE AVELLANEDA, G. Obras escogidas. Pról. de Luisa Campuzano. La Habana: Fondo Editorial Casa de las Américas, 2014a. p. 367-389.

GÓMEZ DE AVELlANEDA, G. Autobiografía. In: GÓMEZ DE AVELLANEDA, G. Obras escogidas. Prólogo de Luisa Campuzano. La Habana: Fondo Editorial Casa de las Américas, 2014b. p. 391-424.

GUTIÉRREZ, J. M. América Poética. Colección escojida de composiciones en verso, escritas por americanos en el presente siglo. Parte Lírica. Valparaíso: Imprenta del Mercurio, 1846.

GUTIÉRREZ, J. M. Archivo. Epistolario, t. 2. Edición a cargo de Raúl J. Moglia y Miguel O. García. Buenos Aires: Biblioteca del Congreso de la Nación, 1981.

INFANTE VARGAS, L. De la escritura personal a la redacción de revistas femeninas. Mujeres y cultura escrita en México durante el siglo XIX. Relaciones, n. 113 (Invierno), p. 69-105, 2008.

LUDMER, J. Tretas del débil. In: GONZÁLEZ, P. E.; ORTEGA, E. (Ed.). La sartén por el mango: encuentro de escritoras latinoamericanas. Río Piedras: Ediciones Huracán, 1985. p. 47-54.

MARÍN DE SOLAR, M. A la Sra. Da. Gertrudis G. de Avellaneda. Página suelta de la Revista del Pacífico, tomo III. Valparaíso: Imprenta y librería del Mercurio, 1860. 
SOBRE A AUTORA

Guadalupe Correa Chiarotti é Professora de Letras (Universidade Nacional de Rosario), tem Mestrado em Estudos da Literatura Mexicana (Universidade de Guadalajara) e Doutorado em Estudos Latino-Americanos (Universidad Nacional Autónoma de México). É professora e pesquisadora em tempo integral (área de pesquisa em Produção Editorial) do Curso de Licenciatura em Letras Hispânicas e da Pós-Graduação em Letras (na linha de Teoria Literária) da Universidad Autónoma Metropolitana-Unidad Iztapalapa. Por 10 anos codirigiu a Editorial Serapis (Argentina). Trabalha com temas relacionados com a historiografia literária e a cultura impressa latino-americana, especialmente antologias, do século XIX. E-mail: lupecorrea@gmail.com.

ORCID: http://orcid.org/oooo-ooo1-9201-4124.

Texto aprovado em 26/10/2021. 